Article

\title{
Links between Attitudes, Mode Choice, and Travel Satisfaction: A Cross-Border Long-Commute Case Study
}

\author{
Philippe Gerber ${ }^{1, *(\mathbb{D})}$, Marius Thériault ${ }^{2}$, Christophe Enaux ${ }^{3}(\mathbb{D})$ and Samuel Carpentier-Postel ${ }^{4}$ (i) \\ 1 LISER-Luxembourg Institute of Socio-Economic Research (LISER), 4366 Esch-sur-Alzette, Luxembourg \\ 2 ESAD/CRAD, Université Laval Québec, Québec, QC G1V 0A6, Canada; marius.theriault@crad.ulaval.ca \\ 3 UMR 7362 LIVE, CNRS, Université de Strasbourg, 67000 Strasbourg, France; \\ christophe.enaux@live-cnrs.unistra.fr \\ 4 ThéMA UMR 6049, CNRS, Université Bourgogne Franche-Comté, 25030 Besançon, CEDEX, France; \\ samuel.carpentier_postel@univ-fcomte.fr \\ * Correspondence: philippe.gerber@liser.lu; Tel.: +352-58-58-55-601
}

Received: 18 September 2020; Accepted: 3 November 2020; Published: 5 November 2020

\begin{abstract}
This paper focuses on a particular form of high mobility, namely the long journeys to work generated by cross-border job market. More precisely, it studies the impact of such behaviors on well-being by analyzing the relationships between mode choice, transport-related attitudes, socio-demographic and spatial attributes, and the level of satisfaction in the context of cross-border long commutes to Luxembourg. The statistical modelling is rooted to a conceptual framework that emphasizes the mutual dependencies between attitudes, mode choice, and satisfaction. Based on a survey among long-distance commuters $(\mathrm{N}=3093)$ held in 2010 and 2011, two ordered logistic regressions, one of which including latent constructs of transport-related attitudes derived from a structural equation modelling, are developed to explain satisfaction in commuting. Main findings are: (1) Travel-related attitudes influence satisfaction with travel more than socio-demographic attributes; (2) public transport users are globally more satisfied in commuting than car drivers; (3) the socio-economic model of satisfaction is plagued by omitted variables issues; (4) the attitude model of satisfaction drops all but one socio-economic attributes (education remains) while improving adjustment (Pseudo-R-squared $=0.57$ versus $0.09 ; \mathrm{BIC}=2953$ versus 6059 ) and avoiding omitted variables bias. The effect of attitudes and other latent constructs is of paramount importance, even concealing most socio-demographic attributes to assess satisfaction. The conclusion is devoted to a discussion on the sustainability of these cross-border long commutes from the individual, social, and environmental points of view.
\end{abstract}

Keywords: cross-border long commutes; Luxembourg; satisfaction; attitudes; mode choice; statistical modelling

\section{Introduction}

Spatial and land use structures evolve thanks to transport networks improvement while tertiary competitive sector concentrates in large cities, often leading to longer commutes [1]. In Europe [2,3], North America [4,5], and Asia [6,7], long commutes provide a substitute to worker migration [8]. In the case of a cross-border job market such as Luxembourg, these long commuting are a way to take advantage of the wage and real estate price differential. However, the spatial mismatch that results from it raises the question of the sustainability of an urban functioning based on a very high demand for mobility. Although more and more studies are devoted to the different forms of high mobility, and in particular long-distance commuting, few works talk about their impacts on travel satisfaction, 
mode choice, and transport attitudes (e.g., [9]), this paper aims at bridging this gap and underline peculiarities of cross-border long commuting in Luxembourg.

Several expressions qualify the phenomenon of high mobility: "mega commuters", "long commuters" [4], "extreme commuters" [10-12], "super-commuters" [13], "inter-jurisdictional commuters" [5], "persevering commuters" [14], or "intensive travelers" [15]. They refer to employees travelling at least two hours total commute per day to reach their workplace and return home. In Luxembourg, with an average daily travel time for journeys to work of $1 \mathrm{~h}$ and $40 \mathrm{~min}$ [16], most cross-border workers rely on long commuting. The number of those workers living in Belgium, France, and Germany commuting to Luxembourg grows steadily, from 105,000 in 2003 to 204,000 in 2020, leading to congestion issues and longer distances.

Using a conceptual framework derived from De Vos and Witlox [17] and Ye and Titheridge [18], this article analyzes the main determinants of the level of travel satisfaction, which contributes to well-being, in the context of long cross-border commuting. Thanks to a two-stage cross-sectional procedure (structural equation model-SEM — and ordered logistic regressions), this research combines sociopsychological constructs to sociodemographic and locational factors to model commuting satisfaction of long-distance commuters. The main purpose is to better understand the impact of long commuting on the satisfaction and eventually improve the attractiveness of public transit for this growing pool of long-distance travelers.

The article is structured as follows. Section 2 presents a literature review, the conceptual framework used for this research, and an operational definition of long commuting in the case of Luxembourg. Section 3 details the methodological procedure. Section 4 shows results and comments on the Luxembourg case. Section 5 discusses the differences between metropolitan and cross-border long-distance commuting. Last, the conclusion focusses on ways to further the research on this topic when (if) longitudinal panel surveys become available.

\section{Interactions between Long Commuting, Satisfaction, and Attitudes}

This section presents a literature review about criteria used to qualify long commutes (Section 2.1), association between long commuting and travel satisfaction (Section 2.2), and research questions (Section 2.3).

\subsection{Extreme-Long-Mega-Commuting}

Grimal [19] states four criteria used by several disciplines to define long commutes: Distance, duration, doing an overnight stay and crossing an international border.

Geographers and transport economists rely mainly on the physical distance to distinguish local versus long-distance trips. The home to work Euclidian distance threshold varies from $50 \mathrm{~km}$ in the Netherlands [20], 50 miles in the USA (US Department of Transportation) to $100 \mathrm{~km}$ in France [21] and Sweden [22].

The second criteria, used mainly by sociologists, relies of travel duration. The threshold is above $90 \mathrm{~min}$ for a one-way trip in the USA [10] or between 100 and $120 \mathrm{~min}$ in Europe [15]. Rapino and Fields [4] combine distance and duration to define mega commuting as "travelling 90 or more minutes and 50 or more miles to work" while extreme commuters are workers "travelling 90 or more minutes" and long commuting means "travelling 50 or more miles".

The third criterion relates to trips involving at least one night outside the main residence, meaning a secondary living place [23] or mobile home [24]. This mobility pattern is often called FIFO (Fly In Fly Out) or DIDO (Drive In Drive Out), a well-known phenomenon in Canada, Australia, and Chile [25]. Going back to their main home during breaks (e.g., weekends), workers choose this commuting strategy to avoid moving out [26]. They seek for better wages [27], but often to the cost of a lower subjective well-being and weaker involvement at work [28]. This criterion considers multi-day commuting while avoiding crossing international boundaries. However, what about multi-country commuting? 
The last criterion defines long commuting crossing an international boundary. Therefore, travelling to a foreign country is assimilated to a long-distance commute [19] without explicit threshold on travel distance and duration. Nevertheless, this criterion can be useful to qualify daily life of cross-border workers. In Europe, cross-border labor markets are growing fast. They involve 1.3 million workers in 2015 [29] in progress from 780,000 in 2006-2007 [30]. Most of them commute over long distance, both in time and distance. For example, in 2010, cross-border workers living in Belgium and working in Luxembourg travel an average of $49 \mathrm{~km}$ (one-way), while workers living and working in Belgium travel an average of $22 \mathrm{~km}$ [16].

Based on distance, travel time and cross-border criteria, we consider that most cross-border workers in Luxembourg are long commuters. Self-declared daily commute distances are roughly similar between car and PT (public transit) users (Median: $84 \mathrm{~km}$; Q1: 62; Q3: 114). However, one-way commute time is higher for PT riders (Median: 71 minutes; Q1: 60; Q3: 85) than car users (Median: 45; Q1: 35; Q3: 60). All commuters satisfy the fourth criterion, and $90 \%$ of them travel distances of more than $50 \mathrm{~km}$ per day and $75 \%$ commute above 80 minutes. They likely experience positive and negative impacts on well-being and satisfaction that may not apply to shorter commuting. Shorter distance commuters are kept in the models to assess the relative effect of commute time on satisfaction.

\subsection{Long Commuting and Satisfaction}

Because travel is a demand derived from an activity and satisfaction is a global subjective assessment of its realization [31], long-commuting often leads to constraints, burden, stress, and time loss associated with lower satisfaction, weaker well-being, and degraded health status. Many researchers report on the correlation between commuting trip duration and the rise of stress and dissatisfaction [32-37]. With working conditions being controlled for, Drobnič et al. [38] report that longer commutes (particularly above 90 minutes) have a detrimental effect on life satisfaction in nine European countries. As well, long commutes lead to higher absenteeism from work [39].

Other papers analyze the qualitative attributes of travel and their impact on satisfaction. Based on a sample of 3409 Canadian commuters travelling by car, Hilbrecht et al. [40] find that quality of the trip experience has more impact on satisfaction than travel time. In fact, travel can generate advantages providing a gap between the home and the workplace or giving time to do other activities like to relax, play, or reinforce social networks [41,42]. To generate benefits, travel time must be adaptable to the user. That can be an incentive to choose public transit to secure free time availability during long commutes.

The embodiment of such benefits is related to the chosen transport mode and the complexity of the trip (e.g., direct versus multiple-stop trip). In most cases, satisfaction of using the public transit is in between driving the car (lowest) and active transportation modes (highest) [43,44]. Nonetheless, active transportation modes are ill-suited for long commuting and often, suitable choices are restricted to motorized modes. In a comparison between motorized modes used for commuting in the New York metropolitan region, Wener and Evans [45] find that car commuters are more stressed than train users, mostly because of unpredictability in road congestion. In the same way, from the user point of view, unpredictable train lines and intercity bus routes (e.g., random delays or low reliance) are less satisfactory [46].

These findings put light on the ambivalent relationship of commuting on satisfaction where attributes of transport mode choice influence travel satisfaction, and vice versa. De Vos and Witlox [17] discuss the bidirectional relationship between trip satisfaction and travel mode choice. Using the 1996 to 2008 waves of the British Household Panel Survey allowing for modelling causality, Dickerson et al. [47] find no link between long commutes and life satisfaction. That is in line with the conclusion of Morris and Zhou [48] based on the American Time Use Survey. Many scholars conclude that, for car commuters, the quality of travel is mostly related to the congestion, variability (e.g., predictability of congestion), trip duration, and mode choice. Therefore, factors driving commuting satisfaction are intertwined and difficult to model $[49,50]$. 
To go further, one should also consider demographic and economic factors, as well as the attitudes towards transportation modes. Indeed, the perceived difference between "a gift" and "a burden" [51] are linked to travel-related attitudes which are better indicators of satisfaction in travel [52].

\subsection{Research Questions}

According to psychosocial theories, attitudes are subjective assessments related to an object or a situation. They display the personal or social desirability of a behavior, the feeling of being (or not) inclined (likeliness) to perform a given action [53].

For decades, several studies used attitudes to explain travel behavior, notably mode choice, in combination with concepts from economic theories, time geography, and psychosocial sciences [54-57]. More recently, Ye and Titheridge [18] develop a conceptual framework, linking attitudes and mobility behaviors stating that the determiners of modal choice can be bidirectional, such as between travel attitudes and the built environment, or between modal choice and travel satisfaction. However, while applying this framework from a survey conducted in Xi'an (China), the specification of the model is simplified, and the relationships remain unidirectional (e.g., travel attitudes explain satisfaction and not the opposite).

This literature review shows that the current state of the art does not address the relationships between travel-related attitudes and satisfaction in a context of long commuting, except for two articles providing some empirical indications. Beck and Hess [58] studied the willingness to accept longer commutes to get better pay, considering the differentiated attitudes between and within couples through an experiment carried out in the Stockholm area. The findings are that, in addition to the marked gender differences, relationships between spouses are often inconsistent, suggesting that attitudes may be complex and difficult to measure. A study conducted in Kunming City (China) focuses on the comparison of travel time attitudes with long trips [6]. The findings show that most long commuters do not idealize their travel time and remain dissatisfied with their journey. Knowing that various contexts could imply different travel choices and perceptions, we retain a conceptual framework considering the specificities of the long commuters and the Luxembourg socio-spatial constraints.

From now, two main research questions emerge from this state of the art. How do social status and spatial constraints combine with attitudes to set commuting satisfaction? The main hypothesis is that these three dimensions remain complementary regardless constraints of long commuting. As a result, several specificities in the explanatory variables could appear with respect to the cross-border context and long commuting, such as a socio-economic status (e.g., age, level of education), playing a lesser role in the explanation of the travel satisfaction.

Integrating these relationships enables assessing the significance of direct, indirect, and total effects of attitudes and constraints on mode choice and satisfaction level likeliness. The next section presents the methodology developed.

\section{Methodology}

The methodology focuses on the presentation of long commuter data used for the modelling framework. The latter combines (1) a SEM that models the structural relationships among attitudes and latent variables of likely behavior (mode choice and satisfaction) and (2) a logistic regression that uses the latent constructs of the SEM to model the marginal impact of socio-economic attributes, local context attitudes, and stated incentives to use public transit on travel satisfaction.

\subsection{Data}

A one-time snapshot survey was conducted among Luxembourg cross-border workers in 2010 and 2011. It covers $90 \%$ of the population of 146,600 cross-border workers within a commuting area that allows one return journey to work per day. The sampling frame controls for socio-demographic factors [59] and was spatially stratified in 25 zones [60] spreading over three bordering countries: France, Germany, and Belgium. Selected at random, 40,000 workers received a self-administered 
pen-and-paper questionnaire dealing with the usual themes of a national transport survey. There were 7235 respondents in this first phase (response rate $>18 \%$ ). The questionnaire had two versions: French and German. Due care was needed to ensure close adequation between terms used to label perception concepts.

A second phase of the survey was undertaken in 2011 to gather the way commuters perceive their daily and residential mobility (duration, cost, and satisfaction), their beliefs about transportation modes, as well as stated incentives to use public transit. This phase was undergone among respondents of the first phase and attracted a response rate of $52 \%$. A link between respondents from both phases yielded 3727 persons who provided the data that could be used for this research [61]. However, considering the long commute distances involved (average of $43.4 \mathrm{~km}$ one way), motorized modes prevail (car $84.9 \%$; intercity bus $5.5 \%$; train $9.3 \%$ ) leaving less than $0.3 \%$ for other modes (Table 1 ). When omitting respondents using active transportation modes (by bike or by foot) or having missing data, the usable sample is 3090 (see Table 2 or Table 3).

Table 1. Descriptive statistics by country of residence (percent of respondents).

\begin{tabular}{|c|c|c|c|c|}
\hline & Belgium & France & Germany & $\mathbf{N}$ \\
\hline Number of respondents & 836 & 1437 & 984 & 3257 \\
\hline \multicolumn{5}{|l|}{ Satisfaction in Commuting } \\
\hline Very unsatisfied & 6.1 & 9.7 & 4.6 & 235 \\
\hline Unsatisfied & 27.4 & 36.6 & 28.6 & 1027 \\
\hline Satisfied & 58.5 & 49.5 & 58.8 & 1764 \\
\hline Very satisfied & 7.9 & 4.2 & 8.0 & 204 \\
\hline \multicolumn{5}{|l|}{ Non-work trip satisfaction } \\
\hline Very unsatisfied & 0.8 & 1.2 & 1.4 & 37 \\
\hline Unsatisfied & 7.0 & 10.9 & 13.7 & 345 \\
\hline Satisfied & 81.3 & 81.1 & 78.5 & 2582 \\
\hline Very satisfied & 10.9 & 6.8 & 6.4 & 249 \\
\hline Public transit user (Dummy; reference car user) & 17.0 & 21.0 & 13.3 & 575 \\
\hline Road distance from home to work (mean; km) & 50.6 & 41.8 & 49.2 & 3252 \\
\hline Self-reported one-way commute duration (mean; mn) & 54.2 & 55.4 & 51.0 & 3115 \\
\hline Work in Luxembourg City (Dummy) & 41.8 & 44.1 & 38.6 & 1363 \\
\hline Parking issues at the workplace (Dummy) & 20.6 & 24.3 & 14.6 & 665 \\
\hline Travel during peak hours (Dummy) & 61.7 & 59.0 & 68.8 & 2037 \\
\hline Access to a firm car (Dummy) & 20.3 & 11.9 & 12.8 & 467 \\
\hline Post-secondary education (Dummy) & 31.2 & 24.4 & 28.1 & 887 \\
\hline Night worker (Dummy) & 7.42 & 12.0 & 10.0 & 332 \\
\hline Motorization deficit in the household (Dummy) & 13.2 & 9.2 & 14.6 & 384 \\
\hline Double earner household (Dummy) & 60.2 & 60.6 & 54.9 & 1914 \\
\hline \multicolumn{5}{|l|}{ Age of the respondent } \\
\hline$<35$ & 24.4 & 25.3 & 20.2 & 766 \\
\hline $35-44$ & 38.0 & 39.0 & 37.0 & 1243 \\
\hline $45+$ & 37.6 & 35.7 & 42.8 & 1248 \\
\hline \multicolumn{5}{|l|}{ Self-reported incentives to use PT for commuting } \\
\hline Develop new services (Car versus PT users: $\chi^{2}: 14.6^{* * *}$ ) & 51.2 & 58.7 & 59.6 & 1857 \\
\hline Car commuters & 53.6 & 60.4 & 60.3 & 1571 \\
\hline PT commuters & 39.4 & 52.3 & 55.0 & 286 \\
\hline Improve Stops (Car versus PT users: $\chi^{2}: 39.7^{* * *}$ ) & 10.4 & 13.1 & 13.8 & 411 \\
\hline Car commuters & 9.5 & 11.5 & 11.3 & 292 \\
\hline PT commuters & 14.8 & 19.2 & 30.5 & 119 \\
\hline Add Seats (Car versus PT users: $\chi^{2}: 184.35^{* * *}$ ) & 23.1 & 28.7 & 10.6 & 709 \\
\hline Car commuters & 19.9 & 23.4 & 6.9 & 463 \\
\hline PT commuters & 38.7 & 48.3 & 34.4 & 246 \\
\hline Lower tariff (Car versus PT users: $\chi^{2}: 13.6^{* * *}$ ) & 34.1 & 28.9 & 24.5 & 941 \\
\hline Car commuters & 30.0 & 27.8 & 24.7 & 735 \\
\hline PT commuters & 54.2 & 32.8 & 22.9 & 206 \\
\hline
\end{tabular}

Significance: ${ }^{* * *} p<0.001$. 
Table 2. Assessment of transport modes using semantic differentials (in \% of respondents; $\mathrm{N}=3090$ ).

\begin{tabular}{|c|c|c|c|c|c|c|c|}
\hline \multicolumn{2}{|c|}{ Assessment of the Train } & \multirow{2}{*}{$\begin{array}{c}\text { Very } \\
3\end{array}$} & \multicolumn{3}{|c|}{ Neutral } & \multicolumn{2}{|l|}{ Very } \\
\hline Comfort & Uncomfortable & & 20 & 31 & 41 & 5 & Comfortable \\
\hline Restfulness & Tiring & 2 & 11 & 22 & 50 & 15 & Relaxing \\
\hline Security & Risky & 1 & 3 & 23 & 47 & 26 & Secure \\
\hline Environmental & Polluting & 3 & 7 & 14 & 50 & 26 & Clean \\
\hline Noise & Noisy & 3 & 23 & 40 & 29 & 5 & Quiet \\
\hline Cost & Expensive & 7 & 30 & 31 & 27 & 5 & Cheap \\
\hline \multicolumn{2}{|c|}{ Assessment of the Car } & Very & & Neutral & & Very & \\
\hline Comfort & Uncomfortable & 4 & 9 & 11 & 42 & 34 & Comfortable \\
\hline Restfulness & Tiring & 14 & 49 & 28 & 8 & 1 & Relaxing \\
\hline Security & Risky & 9 & 37 & 35 & 16 & 3 & Secure \\
\hline Environmental & Polluting & 28 & 52 & 16 & 3 & 1 & Clean \\
\hline Noise & Noisy & 2 & 17 & 45 & 30 & 6 & Quiet \\
\hline Cost & Expensive & 32 & 52 & 12 & 3 & 1 & Cheap \\
\hline
\end{tabular}

Table 3. Ordered logistic regression of commuting satisfaction $(\mathrm{N}=3090)$.

\begin{tabular}{|c|c|c|c|c|c|c|}
\hline & \multicolumn{3}{|c|}{ Socio-Economic Model } & \multicolumn{3}{|c|}{ Attitude Model } \\
\hline & Coefficient & $\mathbf{z}$ & Sign & Coefficient & $\mathbf{z}$ & Sign. \\
\hline Pro-Car Attitude & omitted & & & 5.917 & 26.65 & $* * *$ \\
\hline Train Comfort Attitude & omitted & & & 0.840 & 6.01 & $* * *$ \\
\hline Train Environment Attitude & omitted & & & -1.775 & -12.28 & $* * *$ \\
\hline Propensity to use Public Transit & omitted & & & 6.850 & 23.46 & $* * *$ \\
\hline Public transit user & 1.646 & 13.57 & $* * *$ & -6.868 & -14.88 & $* * *$ \\
\hline Self-reported commute duration & -0.019 & -8.43 & $* * *$ & -0.021 & -9.33 & $* * *$ \\
\hline Road distance from home to work & -0.006 & -2.64 & $* *$ & & & n.s. \\
\hline Country (ref. Belgium) & 1 & & $* * *$ & 1 & & \\
\hline France & -0.755 & -7.94 & $* * *$ & -0.341 & -2.87 & $* *$ \\
\hline Germany & -0.072 & -0.71 & & 0.181 & 1.49 & \\
\hline Work in Luxembourg City & -0.385 & -4.74 & $* * *$ & 0.583 & 5.66 & $* * *$ \\
\hline Travel during peak hours & -0.419 & -4.90 & $* * *$ & -0.372 & -3.65 & $* * *$ \\
\hline Access to a firm car & & & n.s. & & & n.s. \\
\hline Post-secondary education & -0.450 & -5.51 & $* * *$ & -0.568 & -5.39 & $* * *$ \\
\hline Night worker & 0.307 & 2.27 & * & & & n.s. \\
\hline Age of the respondent (ref. <35) & 1 & & & & & n.s. \\
\hline $35-44$ & 0.000 & 0.00 & & & & n.s. \\
\hline $45+$ & 0.236 & 2.46 & * & & & n.s. \\
\hline Motorization deficit in the household & 0.252 & 2.15 & * & & & n.s. \\
\hline Must add seats in PT vehicles & -0.370 & -3.83 & $* * *$ & -0.301 & -2.30 & $*$ \\
\hline Must develop new PT services & -0.388 & -5.27 & $* * *$ & & & n.s. \\
\hline Cut: Highly unsatisfied / Unsatisfied & -3.507 & & & -7.960 & & \\
\hline Cut: Unsatisfied / Satisfied & -0.720 & & & -2.702 & & \\
\hline Cut: Satisfied / Highly satisfied & 3.638 & & & 4.592 & & \\
\hline Wald $\mathrm{Chi}^{2}$ & 470 & df: 14 & & 979 & df: 13 & \\
\hline Pseudo $\mathrm{R}^{2}$ & 0.0900 & & & 0.5700 & & \\
\hline AIC & 5956 & & & 2856 & & \\
\hline BIC & 6059 & & & 2953 & & \\
\hline Link test (model specification) & Failed & Prob. : & 0.007 & OK & Prob. : & 0.596 \\
\hline
\end{tabular}

Significance: ${ }^{*} p<0.05 ;{ }^{* *} p<0.01 ;{ }^{* * *} p<0.001$.

Despite its size (sampling fraction is about $2 \%$ ), this sample was found representative of the cross-border workers in Luxembourg on both socioeconomic and home location criteria [59]. 
Among users of $\mathrm{PT}, 60 \%$ access the nearest intercity bus stop or train station by driving a car (park and ride), $4.9 \%$ are car passengers (kiss and ride), leaving a mere $27.5 \%$ for active transportation modes and city buses (7.6\%). In this study, car ownership is widespread (99.3\% of the households). Cross-border workers live in France (50.1\%), Belgium (25.8\%) and Germany (24.1\%). Mode shares of intercity bus and train vary between country (which indicates differences in supply) and between Luxembourg City (above 35\% for PT) and other locations within Luxembourg (above 94\% of car users). Moreover, one can note that incentives to ride PT are significantly different between car users and PT commuters (Table 1).

During phase 2, respondents were asked to select (multiple choices) among 12 factors that, in their opinion, could convince car users to use PT more often. Incentives shown at the end of Table 1 generate significant difference between car versus PT users. Unfortunately, we must use dummy variables while better information (e.g., order or importance degree) would been more appropriate. Car users ask for more services while PT users are more focused on operation (stops), comfort, and cost (except in Germany).

\subsection{Modeling Framework}

Our methodological framework (Figure 1) relies on two complementary steps. The first is a preliminary analysis of the satisfaction towards commuting based on a SEM. It allows to assess the bidirectional relationship between mobility behavior, attitudes, and satisfaction and to extract latent constructs that summarizes individual's attitudes towards transport mode. The second step includes latent constructs and measured variables to model the level of satisfaction.

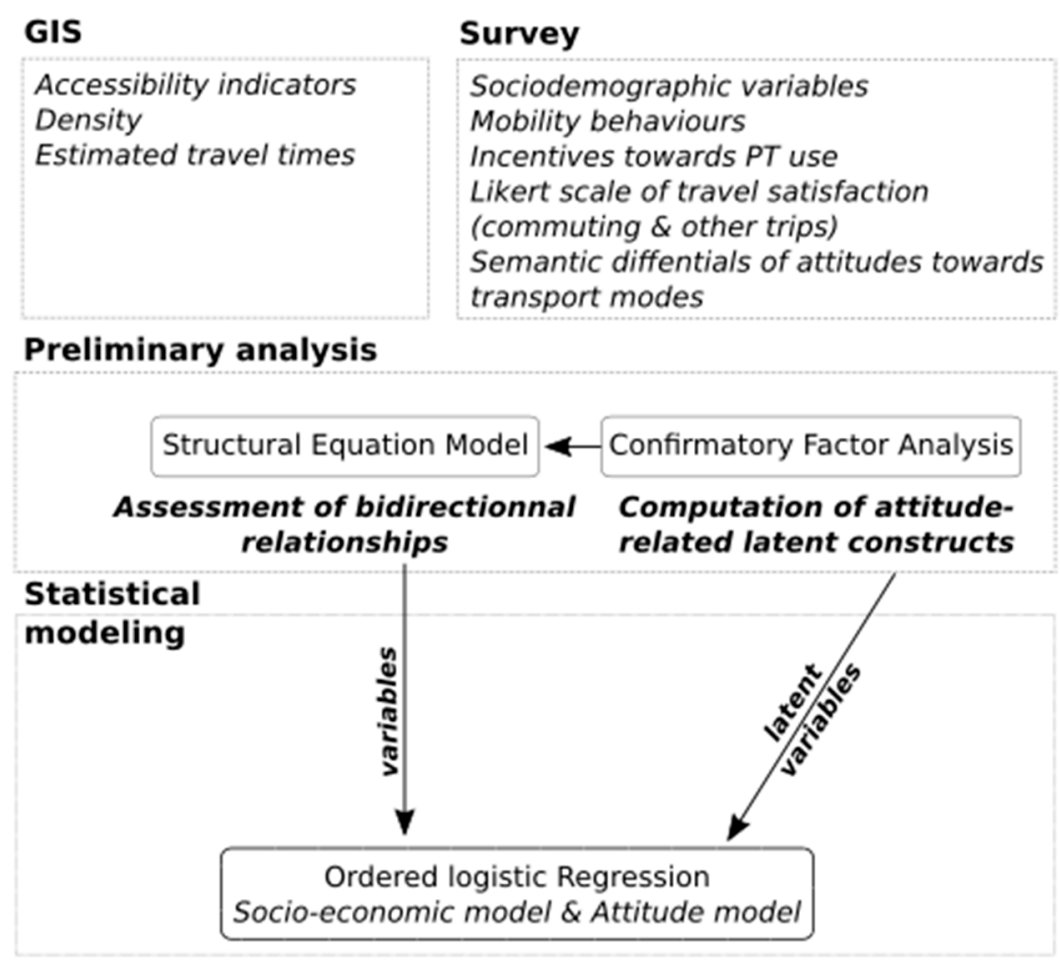

Figure 1. Methodological framework.

Respondents of the second phase survey were asked to assess their beliefs (measurement indicators) about the car and the train on six criteria using 5-level semantic differentials (Table 2). Assessments of security, cost, environmental impact, restfulness, comfort, and noise are combined using a confirmatory factor analysis (CFA, results not shown) to define a measurement model [62] yielding three latent variables related to a pro-car, a train-comfort, and a train-environment attitude (see Appendix A). 
The SEM combines a measurement model (CFA) with a structural model (SEM) to handle the relationships among the latent variables, especially the travel-related attitudes, and the travel satisfaction and the mode choice. If latent variables are specified, their values (parameters and scores) are estimated to optimize the adjustment with the data using a maximization rule [62] and can be used as explanatory variable in other statistical models.

The SEM is estimated using numerical fit methods. The most used fit method, maximum likelihood (ML), assumes normality of indicators. Since indicators of Tables 1 and 2 are not normally distributed, a quasi-maximum likelihood (QML) estimation was performed and the computation of standard errors uses the Huber-White sandwich estimator of the covariance matrix to compute fit indices and standard errors [63]. Estimation of the SEM is done with Stata release 15 using QML.

For this research, the SEM integrates the reflexive CFA of attitudes towards transport modes with: (1) Satisfaction in travel (combining commuting and other trips) combined into a reflexive model of satisfaction with travel; (2) use of public transit to commute; (3) propensity to use PT influenced by the pro-car and train-comfort attitudes in interaction with satisfaction with travel; and (4) three exogenous variables describing core aspects of travel to work (the destination-Luxembourg City, the peak hour effect, the contingency of access/responsibility of a firm car). The endogenous variables influence both the use of PT and the satisfaction in commuting.

The set of equations (Appendix A) defines direct and indirect paths of dependency for assessing mediation, while the reciprocal feedback of satisfaction with travel and propensity to use PT allows for moderation in a non-recursive SEM (stability index is well below 1). After model calibration, latent variables are predicted and standardized. Their scores are later used in the ordered logistic regression models of satisfaction (see distributions in Appendix B).

The second and last step of our methodology consists in modelling the level of satisfaction of cross-border commuters regarding their journeys to work. This model uses as the dependent variable the self-reported satisfaction in commuting using an ordered 4-class scale from "very unsatisfied" to "very satisfied" (see Table 1). More precisely, two ordered logistic regressions are used: The first, called socio-economic, relates satisfaction to the home country, trip to work characteristics, socio-economic attributes, stated incentives to use PT; the second model, called attitudes, adds latent transport-related attitudes and propensity to use PT coming from the SEM in order to compare it with the first.

Ordered logit models estimate parameters of the relationships between an ordered dependent variable and a set of independent variables [64]. It is a generalization of the binary logit model that is estimated using maximum log likelihood [65]. An underlying score is estimated as a linear function of the independent variables and a set of cut points between classes. An ordered logit model provides odds ratios to compute the marginal probability of class membership linked to each variable/indicator. Standard errors of coefficients are used to test for the significance of each indicator and variable. Moreover, it allows Wald tests to assess the significance of specific sets of variables [66].

\section{Results}

\subsection{Structural Equation Model}

Figure 2 and Appendix A presents the cross-sectional SEM results. The fit is very good by all criteria (CFI, RMSEA, SRMR, R-squared [CD], and Stability). That indicates a close agreement with the covariance matrix of measurement and exogenous variables. Figure 2 shows the significant $(p<0.05)$ relationships. All coefficients are in line with expectations and significant at the $1 \%$ rejection level or below. For example, travel during peak hours increases PT ridership. PT services are better suited for commuting to Luxembourg City yielding a positive effect on PT mode share, but slightly decrease satisfaction (more congestion). Access to a firm car has a negative effect on both satisfaction (restricted more choice when you must drive a car) and use of PT for commuting. 


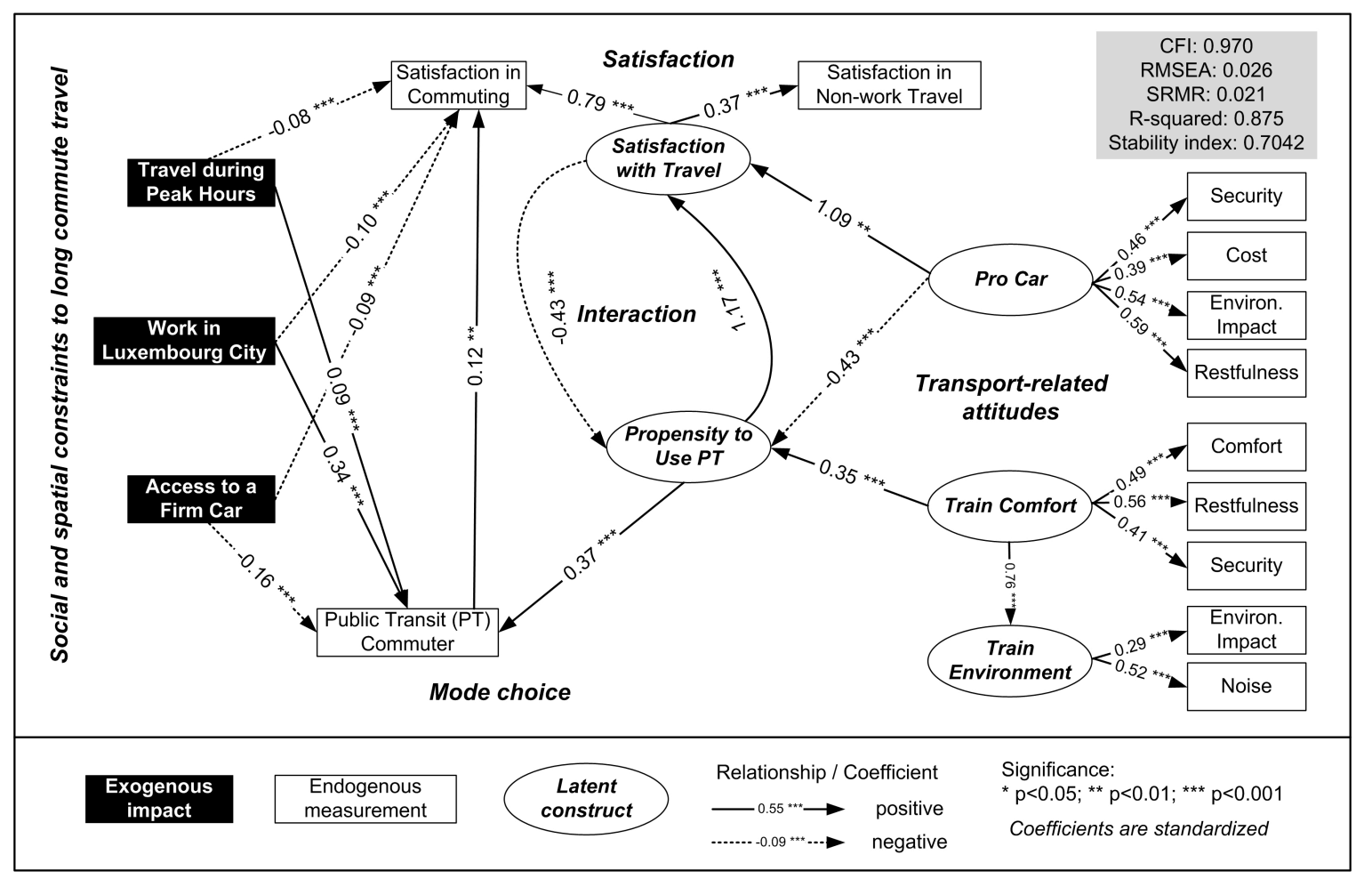

Figure 2. SEM of attitudes, commute choice and satisfaction with travel $(\mathrm{N}=2859)$.

As expected, travel-related attitudes are related to mode choice (propensity) and satisfaction with travel (and commuting). Some of these relationships are direct and appear in Figure 2. However, many effects of pro-car and train-comfort attitudes on satisfaction in commuting and actual mode choice are mediated by latent variables (mostly satisfaction with travel and propensity to use PT) as can be seen in the last column in Appendix A Table A1 (total effects). For example, a positive train-comfort attitude increases PT commuting while a pro-car attitude is detrimental. The large difference in coefficients for the propensity to use PT as a predictor of PT use, from 0.3687 for the direct effect up to 0.6685 for the total effect, indicates a large share of mediation. Finally, a positive train-environment attitude shows no significant effect on the propensity to use PT.

\subsection{Ordered Logistic Model of Commute Satisfaction}

When including the standardized attitude scores, the ordered logit model performs much better than without the scores (Table 3). The attitude model is far more efficient with the latent constructs $\left(R^{2}=0.57\right.$, without latent constructs $\left.R^{2}=0.09\right)$ and better adjusted $(B I C=2953$, without $B I C=6059)$ than the socio-economic model. Furthermore, the link test indicates that the model without attitudes is likely plagued by the omitted variables issue.

Moreover, all but one (education) socio-economic attributes lose their significance when attitudes (latent variables) are set in the model. Attitudes are highly significant and outperform most other variables. The most resilient measured variables relate to the trip itself: Mode choice and road distance from home to work. Moreover, two important coefficients change signs from the socio-economic to the attitude model: Mode choice (use of PT) and work in Luxembourg City. One should remember that these variables are included in the SEM and mediated by the predicted factors: The coefficients of the latter model express their remaining marginal effect after the attitudes are considered.

Then, while using PT for commuting increase satisfaction in the first model, the same variable competes with the propensity to use public transit in the attitude specification. Signs are reverse and of the same magnitude, meaning that the global impact on satisfaction is null for PT users with a 
standardized propensity score of 1 , positive for consonant PT users (score above 1 ), and negative for dissonant PT users (propensity score below 1).

Through mediation, the SEM embeds this higher satisfaction into the propensity to use PT unveiling the differences between car and PT users. Their likelihood to be satisfied takes opposite signs. Reminding that propensity is a standardized variable (with values between -4 and +4 ; see Appendix B Figure A1), for PT users, the positive effect on satisfaction happens when the propensity to use PT is higher than 1 (6.850-6.868). Conversely, for car users, the positive effect on satisfaction occurs when the propensity to use the PT is lower than. Therefore, consonance (i.e., an agreement between an attitude and a behavior) and free-choice opportunity matter.

Working in Luxembourg City shows a similar behavior. When the negative externality of travelling to the main city (e.g., congestion) is cancelled out in the propensity to use PT, the positive externality of a wider mode choice (better PT supply + the car) becomes visible because these workers can optimize their decision when they are successful to avoid congestion (peak hours remain significant). Additionally, detrimental effects of trip duration and living in France remain highly significant. The effect of trip duration is as expected: The more it takes time, the less the commuter is satisfied.

\section{Findings and Discussion}

\subsection{Summary of Findings}

The main findings are:

- Travel-related attitudes influence satisfaction with travel. The pro-car attitude competes with pro-train attitudes (opposite signs) to "explain" commuting satisfaction.

- Long commute during peak hours is detrimental to satisfaction of car users and increase PT ridership where PT service is efficient and abundant (e.g., working in Luxembourg City). Thus, the propensity to use PT increases satisfaction in commuting if riders are consonant (positive attitude about the train).

- $\quad$ PT riders are globally more satisfied in commuting than car users. That is highly significant in the socio-economic model. However, that relationship reverses when considering attitudes and propensity to use $\mathrm{PT}$, meaning that consonant riders are more satisfied.

- Access to a firm car has no marginal effect on satisfaction in commuting while it closely impedes using the PT. That suggests a perceived balance between benefits when traffic is free flow and inconvenience when road congestion occurs.

- Satisfaction including travel-related attitudes and the linkage with the other component (as a latent variable) are better adjusted and much more informative than mere socio-economic models.

- The attitude model of satisfaction in commuting drops all but one socio-economic attributes (education remains) while improving adjustment (R-squared increased from 0.09 to 0.57; BIC decreased from 6059 to 2953).

- For this case study, standard socio-economic models of satisfaction are plagued by omitted variables issues. Thus, travel-related attitudes highly matter while their impact can also be mediated by other latent constructs.

- Latent variables assessing the propensity to use PT and travel satisfaction are mutually dependent in the cross-sectional SEM. That supports part of the conceptual framework. These latent constructs mediate the influence of travel-related attitudes in the SEM. That is in line with expected mediation and self-moderation effects.

The Luxembourg case confirms the relevance for adding attitudes in the satisfaction model: It reshapes the scope of socio-economic effects in favor of attitudes and propensity (partially handling the impact of consonance). 


\subsection{Discussion}

Cross-sectional models were rather efficient to disentangle the complex relationship between mode choice and satisfaction. In relative terms, PT commuters tend to be more satisfied than car users as measured in the socio-economic model (they avoid road congestion close to Luxembourg City). That is in contrast with the literature review carried out by De Vos [44]. Considering 29 articles, 17 articles find that car travel was more satisfactory than using PT when excluding active transportation modes that are widely preferred. However, most of these studies are about metropolitan commuting where active transportation modes are a feasible alternative. That is illustrative of the difference between long-distance, cross-border, and metropolitan commuting.

Observed differences lead to two complementary hypotheses to be verified in future research: (1) The PT services to Luxembourg are efficient and mostly reliable because they link high-density remote towns in neighbor countries to concentrated workplaces (bicentric labor market) with few intermediate stops (thanks to the rural landscape on the way); (2) there are few commuting road axes to reach work centers, leading to congestion at peak time. That is in contrast with long-commuting in most metropolitan areas where PT must be designed to service multiple stops along the railroad or bus line. In fact, the studied PT network shows some attributes of a de facto transit-oriented development (TOD) system centered on Luxembourg while traffic on the highways is unidirectional and thus unbalanced during peak hours. Despite freeness of travel in the Schengen zone, this setting is to be contrasted with that of metropolitan areas crossing provinces in Canada (e.g., Ottawa-Gatineau), states in the U.S. (e.g., New York-Newark), or even international borders (e.g., Detroit-Windsor). In all those cases, urbanization is continuous and commuters exchange is somewhat bi-directional. Furthermore, the cultural differences experienced by Luxembourg are undoubtedly stronger than the cases across the Atlantic mentioned. For example, these differences can be linked to language and are reflected in the labor market. The increasing number of cross-border workers is prompting substantial change to Luxembourg's traditionally triglossic language situation, where Luxembourgish, French, and German have coexisted in public use (see e.g., $[67,68]$ ). In addition to this cultural diversity are the different activity and transportation practices of the residents of the three countries. French cross-border commuters, who are more inclined to take PT, are nonetheless the most dissatisfied, due in particular to greater road congestion, the higher density of the resident population, and the number of cross-border commuters.

This case study illustrates the specificities that should be considered for studying long commuting. Many socio-economic variables (e.g., gender, age, full-time versus part-time jobs, income, car ownership, living place and urban forms, children at home, household structure, etc.) were tested in the models. However, they were nonsignificant or gradually dropped when considering attitudes and propensities that are based on psychosocial measurements in the satisfaction model. That is to put in contrast with findings of Zhu and Fan [69], Roberts et al. [70], Cao and Ettema [71], Mouratidis et al. [72], and Ye and Titheridge [73] where socio-economic features or built environment matter.

That may result from two sources: (1) Despite its multinational structure, the cross-border labor market of Luxembourg is rather homogenous: Cross-border workers are less strongly polarized in skills and occupations and with lower within-group wage inequality than immigrants living and working in Luxembourg [74]. (2) Considering only long-distance (and motorized) travel, the study emphasizes the differentiation of attitudes in a region made of four countries and several languages or cultures (mostly German and French). This feature needs further experiments (compare cross-border workers and Luxembourg citizens) and other case studies in similar contexts (e.g., Geneva).

All in all, we believe that our results based on cross-sectional data support the conceptual framework proposed by De Vos [44], De Vos and Witlox [17], and Ye and Titheridge [18]. However, longitudinal data, especially panel surveys, are needed to fully explore the causal structure of relationships between the socio-economic status, beliefs and attitudes, transportation choices, and satisfaction. The framework assumes that many relationships are bidirectional leading to mutual dependency. However, Heinen and Bohte [75] state that the direction of causality between 
attitudes and behavior in travel mode choice and commuting is a matter for debate. Attitudes affect behavior, as many psychological theories purport, but behavior also could influence attitudes.

Moreover, it appears that long-distance commutes are somewhat different from intra-metropolitan commutes and that these peculiarities could be related to specificities like the structure of the labor market. The willingness to commute for long distances is likely related to other basic attitudes that may be common to most long-distance commuters. Thus, latent-class analyses based on economic sectors, types of employment (e.g., professionals versus manual workers), beliefs, values, and attitudes about lifestyle (e.g., family, social rank, salary levels, etc.) can likely improve: (i) Understanding personality traits of the commuters and (ii) assessing dissonance and consonance [76].

Increasing ridership of electric transport modes (like the train) and reducing road congestion are paramount factors to better sustainability of long commuting. Our findings show that satisfaction is highly related to consonance (attitudes versus actual mode choice) while increasing comfort (e.g., adding seats) in PT vehicles may have a significant marginal impact on satisfaction. Table 3 reports a lower satisfaction in commuting for commuters asking for more seats $(p<0.05)$. That should be interpreted in conjunction with Table 1 indicating that it is mostly a demand from PT users. Filling such a need allows for enhancing the attitude towards the train comfort, which can also raise consonance. However, further studies are needed to choose which PT routes or service to prioritize.

Some limitations can be mentioned concerning this study. For example, survey data are 9 to 10 years old. Nevertheless, considering the cost of such national-level survey, the GIS analysis needed to locate respondents, describe their living context, and summarize their access to transport means, we believe that these data are still relevant. In addition, the collection of attitudinal data on transport modes, related to satisfaction, is not a common practice in national or regional transport surveys. As a result, the information provided by this survey is not yet updated at this scale of precision (local) and magnitude (three different countries covered). Moreover, redoing similar survey and analysis after the COVID-19 pandemic could be interesting to seek differences.

\section{Conclusions}

Combining GIS data with a survey within two models, this article analyses linkages between mode choice, attitudes about transportation modes, and travel satisfaction for high mobile cross-border commuters. This research's originality pertains to the geographical scale of analysis associated with long-distance commuters living outside the Luxembourg metropolitan area (and country).

Despite limitations coming from the age of data and its cross-sectional nature, including reflexive attitude variables and formative latent indicators of mode choice is still meaningful and strongly improves the regression models, both in terms of functional form relevance and of adjustment. The impact of latent constructs of attitudes is highly significant on commuting satisfaction, which could impact well-being. Only one sociodemographic variable (education) remains significant in the attitude model, meaning that attitudes supersede the other sociodemographic attributes and the main drivers of commuting satisfaction.

Overall, considering unavailability of active transportation modes and the dominance of the car, it appears that PT users are more satisfied with commuting, likely because during long commutes it provides free time and restfulness, necessary to enhance the subjective well-being. Nevertheless, depending on the current COVID-19 pandemic crisis, changes in daily travel patterns could have an impact on travel satisfaction, particularly through a reduction in the number of daily commutes [77]. Indeed, teleworking is likely to be more developed than it was in most countries: This might be the case in Luxembourg, even on a cross-border scale. With a strong decrease in congestion, especially towards city centers, it is possible that car user satisfaction will improve. Moreover, contagion makes the use of PT more risky from a health point of view. How does this affect the feeling of safety and the positive image of PT, even if they are efficient? Beyond the satisfaction measurement, in the coming years, which are the jobs that will be concerned by these telework actions that could reshape the outline of possible new travel patterns and new residential geography? In this sense, our study provides 
a benchmark for comparing the situation before and after the pandemic. This is another research potential that could use a survey of the same type as the one carried out in 2011.

Author Contributions: Conceptualization, P.G. and M.T.; methodology, M.T.; software, M.T.; validation, M.T., P.G., S.C.-P. and C.E.; formal analysis, M.T.; investigation, P.G.; resources, P.G.; data curation, M.T.; writing-original draft preparation, M.T. and P.G.; writing-review and editing, M.T., P.G., S.C.-P. and C.E.; visualization, M.T.; supervision, P.G.; project administration, P.G.; funding acquisition, P.G. All authors have read and agreed to the published version of the manuscript.

Funding: This paper is registered as part of the Prof. Marius Thériault visiting professor scheme held at LISER in 2015 and is linked to the CONNECTING research project (Consequential Life Cycle Assessment of multimodal mobility policies - the case of Luxembourg, FNR CORE C14/SR/8330766). The used database relies on the work of the CABaC 2010-2013 research project (Construction and Analysis of a Knowledge Base on mobility habits and attitudes towards energy of cross-border workers in Luxembourg, FNR INTER/CNRS/09/01). The survey was funded by the Ministry of Higher Education of Luxembourg.

Conflicts of Interest: The authors declare no conflict of interest.

\section{Appendix A. The Structural Equation Model}

\section{Appendix A.1. Model Specification and Fit Indexes}

A Confirmatory Factor Analysis (CFA) is used to define three transport-related attitudes: Pro-Car $\left(L_{1}\right)$, Train Comfort $\left(L_{2}\right)$ and Train Environment $\left(L_{3}\right)$. They are made of reflective structures of measurements that split variations into congruent and error components, providing coefficients (with significance) to estimate the factors and error terms to handle the specificities:

$$
y_{1}=\alpha_{1}+\lambda_{1} L_{x}+\varepsilon_{1}, y_{2}=\alpha_{2}+\lambda_{2} L_{x}+\varepsilon_{2}, \ldots, y_{n}=\alpha_{n}+\lambda_{n} L_{x}+\varepsilon_{n}
$$

where $y_{1}, y_{2}$ and $y_{n}$ are the $n$ indicators used to define the latent variable, $\alpha_{1}, \alpha_{2}$ and $\alpha_{n}$ are intercepts that estimate the expected value of each indicator when $L_{x}$, the latent variable, is zero. $\lambda_{1}, \lambda_{2}$ and $\lambda_{n}$ index the relation between each indicator and the latent variable. $\varepsilon_{1}, \varepsilon_{2}$ and $\varepsilon_{n}$ are independent error terms for each indicator, meaning that any covariance between the indicators belongs to the latent variable.

Cronbach's alpha coefficients provide a measure of internal consistency and reliability to select the indicators to be combined in latent variables. Later, the measurement model is integrated in the SEM to handle (in the structural model) the effect of attitudes on the likelihood to use PT and be satisfied with commute travel.

The SEM integrates the reflexive CFA of attitudes towards transport modes with: (1) satisfaction in commuting $\left(y_{10}\right)$ and in non-work travel $\left(y_{11}\right)$ combined into a reflexive model of satisfaction with travel $\left(L_{4}\right) ;(2)$ use of public transit to commute $\left(y_{12}\right)$; (3) propensity to use PT $\left(L_{5}\right)$ influenced by the pro-car $\left(L_{1}\right)$ and train-comfort $\left(L_{2}\right)$ attitudes in interaction with satisfaction with travel $\left(L_{4}\right)$. Finally, three exogenous variables describing important aspects of travel to work (the destination, Luxembourg City $\left(x_{1}\right)$, the peak hour effect $\left(x_{2}\right)$, the contingency of access/responsibility of a firm car $\left.\left(x_{3}\right)\right)$. The endogenous variables influence both the use of PT and the satisfaction in commuting. Formally:

$$
\begin{aligned}
& y_{1}=\alpha_{1}+\lambda_{1} L_{1}+\varepsilon_{1}, y_{2}=\alpha_{2}+\lambda_{2} L_{1}+\varepsilon_{2}, y_{3}=\alpha_{3}+\lambda_{3} L_{1}+\varepsilon_{3}, y_{4}=\alpha_{n}+\lambda_{4} L_{1}+\varepsilon_{4} \\
& y_{5}=\alpha_{5}+\lambda_{5} L_{2}+\varepsilon_{5}, y_{6}=\alpha_{6}+\lambda_{6} L_{2}+\varepsilon_{6}, y_{7}=\alpha_{7}+\lambda_{7} L_{2}+\varepsilon_{7} \\
& y_{8}=\alpha_{8}+\lambda_{8} L_{3}+\varepsilon_{8}, y_{9}=\alpha_{9}+\lambda_{9} L_{3}+\varepsilon_{9} \\
& L_{3}=\alpha+\beta_{1} L_{2}+\varepsilon \\
& y_{11}=\alpha_{11}+\lambda_{11} L_{4}+\varepsilon_{11} \\
& L_{4}=\alpha+\beta_{1} L_{1}+\beta_{2} L_{5}+\varepsilon \\
& L_{5}=\alpha+\beta_{1} L_{1}+\beta_{2} L_{2}+\beta_{3} L_{4}+\varepsilon \\
& y_{12}=\alpha+\beta_{1} L_{5}+\beta_{2} x_{1}+\beta_{3} x_{2}+\beta_{4} x_{3}+\varepsilon \\
& y_{10}=\alpha_{10}+\lambda_{10} L_{4}+\beta_{1} x_{1}+\beta_{2} x_{2}+\beta_{3} x_{3}+\beta_{4} y_{12}+\varepsilon_{10}
\end{aligned}
$$


where $\alpha, \beta_{x}$ and $\varepsilon$ are, respectively, the intercept, the slopes and the error term of each equation. In this SEM, $L_{4}$ and $L_{5}$ are reciprocally dependent, $L_{4}$ overlaps the measurement and the structural models and $L_{3}$ is dependent of $L_{2}$.

The assessment of fit needs a mix of indices. This paper uses four fit indices. The root mean squared errors of approximation (RMSEA) assesses how well the model, with optimally chosen parameter estimates, would fit the population's covariance matrix. A maximum cut-off value of 0.06 is recommended [78]. The standardized root mean squared residual (SRMR) provides the squared root of the difference between the residuals of the sample covariance matrix and the hypothesized covariance model. A value below 0.05 indicates a well-fitted model. Both RMSEA and SRMR are absolute fit indices and should be complemented with a relative fit index like comparative fit index (CFI). CFI assumes that all latent variables are uncorrelated, and it compares the sample covariance matrix with this null model. A value above 0.95 is indicative of good fit. Finally, the coefficient of determination (R-squared) indicates the global strength of the structural model. It ranges from 0 to 1 (perfect adjustment).

Appendix A.2. Numerical Results

Table A1. Standardized SEM of attitudes towards mode choice and travel satisfaction (N: 2859).

\begin{tabular}{|c|c|c|c|c|}
\hline Measurement Model & Coefficient & $\mathbf{z}$ & Sign. & Total Effects \\
\hline \multicolumn{5}{|c|}{ Pro Car Attitude } \\
\hline Car security & 0.4577 & 18.24 & $* * *$ & 1 \\
\hline Constant & 2.8475 & 81.70 & $* * *$ & \\
\hline Car cost & 0.3900 & 16.10 & $* * *$ & 0.7381 \\
\hline Constant & 2.3608 & 66.19 & $* * *$ & \\
\hline Car environmental impact & 0.5433 & 20.18 & $* * *$ & 0.9730 \\
\hline Constant & 2.5222 & 66.49 & $* * *$ & \\
\hline Car restfulness & 0.5905 & 18.76 & $* * *$ & 1.1417 \\
\hline Constant & 2.7866 & 74.65 & $* * *$ & \\
\hline \multicolumn{5}{|c|}{ Train Comfort Attitude } \\
\hline Train comfort & 0.4927 & 15.22 & $* * *$ & 1 \\
\hline Constant & 3.5461 & 72.29 & $* * *$ & \\
\hline Train restfulness & 0.5563 & 17.94 & $* * *$ & 1.1506 \\
\hline Constant & 3.9068 & 60.64 & $* * *$ & \\
\hline Train security & 0.4070 & 13.75 & $* * *$ & 0.7264 \\
\hline Constant & 4.8914 & 65.80 & $* * *$ & \\
\hline Train noise & & & $* * *$ & 0.4691 \\
\hline \multicolumn{5}{|c|}{ Train Environment Attitude } \\
\hline Train environmental impact & 0.2903 & 9.48 & $* * *$ & 1 \\
\hline Constant & 4.0666 & 52.96 & $* * *$ & \\
\hline Train noise & 0.5236 & 11.07 & $* * *$ & 1.6697 \\
\hline Constant & 3.4831 & 77.09 & $* * *$ & \\
\hline \multicolumn{5}{|c|}{ Satisfaction with Travel } \\
\hline Satisfaction in Commuting & \multicolumn{3}{|c|}{ See structural model } & \\
\hline Non-work Travel Satisfaction & 0.3661 & 7.12 & $* * *$ & \\
\hline Constant & 6.1694 & 43.09 & $* * *$ & \\
\hline \multicolumn{5}{|c|}{ Non-work Travel Satisfaction (Very unsatisfied-very satisfied) } \\
\hline Satisfaction with Travel & & & $* * *$ & 0.2056 \\
\hline Propensity to use Public Transit & & & $* *$ & 0.9540 \\
\hline Train Comfort Attitude & & & $* * *$ & 0.1040 \\
\hline Pro-Car Attitude & & & $* * *$ & 0.1617 \\
\hline
\end{tabular}


Table A1. Cont.

\begin{tabular}{|c|c|c|c|c|}
\hline Structural Model & Coefficient & $\mathbf{z}$ & Sign. & Total Effects \\
\hline \multicolumn{5}{|c|}{ Propensity to use Public Transit $\left[R^{2}: 0.09\right]$} \\
\hline Satisfaction with Travel & -0.4255 & -10.65 & $* * *$ & -0.0714 \\
\hline Train Comfort Attitude & 0.3458 & 5.94 & $* * *$ & 0.0729 \\
\hline Pro-Car Attitude & -0.4296 & -4.26 & $* * *$ & -0.1991 \\
\hline Propensity to use Public Transit & & & $* * *$ & -0.3315 \\
\hline \multicolumn{5}{|c|}{ Satisfaction in Commuting [ $\left.R^{2}: 0.67\right]$ (Very unsatisfied-very satisfied) } \\
\hline Satisfaction with Travel & 0.7918 & 15.53 & $* * *$ & 0.6524 \\
\hline Public transit commuter (Dummy) & 0.1209 & 2.66 & $* *$ & 0.2242 \\
\hline Work in Luxembourg City (Dummy) & -0.0980 & -3.93 & $* * *$ & -0.0830 \\
\hline Travel during peak hours (Dummy) & -0.0822 & -4.49 & $* * *$ & -0.1059 \\
\hline Access to a firm car (Dummy) & -0.0876 & -4.36 & $* * *$ & -0.2159 \\
\hline Constant & 3.7671 & 63.64 & $* * *$ & \\
\hline Propensity to use Public Transit & & & $* * *$ & 3.2517 \\
\hline Train Comfort Attitude & & & $* * *$ & 0.3544 \\
\hline Pro-Car Attitude & & & $* * *$ & 0.4812 \\
\hline \multicolumn{5}{|c|}{ Satisfaction with Travel $\left[R^{2}: 0.28\right]$} \\
\hline Propensity to use Public Transit & 1.1654 & 3.51 & $* * *$ & 3.1018 \\
\hline Pro-Car Attitude & 1.0948 & 3.36 & ** & 0.5259 \\
\hline Train Comfort Attitude & & & ** & 0.0729 \\
\hline Satisfaction with Travel & & & $* * *$ & -0.3315 \\
\hline \multicolumn{5}{|c|}{ Train Environment Attitude $\left[R^{2}: 0.58\right]$} \\
\hline Train Comfort Attitude & 0.7621 & 10.57 & $* * *$ & 0.4691 \\
\hline \multicolumn{5}{|c|}{ Public transit commuter [ $\left.R^{2}: 0.33\right]$ (Dummy) } \\
\hline Propensity to use Public Transit & 0.3687 & 11.91 & $* * *$ & 0.6685 \\
\hline Work in Luxembourg City (Dummy) & 0.3363 & 21.01 & $* * *$ & 0.2625 \\
\hline Travel during peak hours (Dummy) & 0.0939 & 6.08 & $* * *$ & 0.0757 \\
\hline Access to a firm car (Dummy) & -0.1636 & -15.10 & $* * *$ & -0.1775 \\
\hline Constant & 0.1229 & 5.06 & $* * *$ & \\
\hline Satisfaction with Travel & & & $* * *$ & -0.0714 \\
\hline Train Comfort Attitude & & & $* * *$ & 0.0729 \\
\hline Pro-Car Attitude & & & $* * *$ & -0.1991 \\
\hline
\end{tabular}

Significance: ${ }^{* * *} p<0.001 ;{ }^{* *} p<0.01$; Latent variables are in italics CFI: 0.970; RMSEA: 0.026; SRMR: 0.021; CD: 0.875; Stability index: 0.7042; Total effects are unstandardized.

\section{Appendix B. Distributions of the Latent Variables}

Figure A1 shows the box plots of standardized predicted scores for the transport-related attitudes according to home countries, commuting mode choice and commute satisfaction. Slight differences between countries include a lower pro-car attitude in France. There is an inverse relationship between the pro-car attitude and the use of PT while positive attitudes about trains increase the likelihood to ride PT. Finally, the satisfaction is higher for respondent showing a positive transport-related attitude for both the car and the PT.

Figure A2 shows the box plots of the propensity to use PT and travel satisfaction (standardized scores). One can see slight differences between countries, the close adjustments between propensity to use PT and travel satisfaction and commuting satisfaction. They indicate goodness of fit in the SEM. It is even more relevant to look at the adjustment between propensity to use PT and commute satisfaction. As well, the variability of travel satisfaction appears larger for car users than for PT riders. 


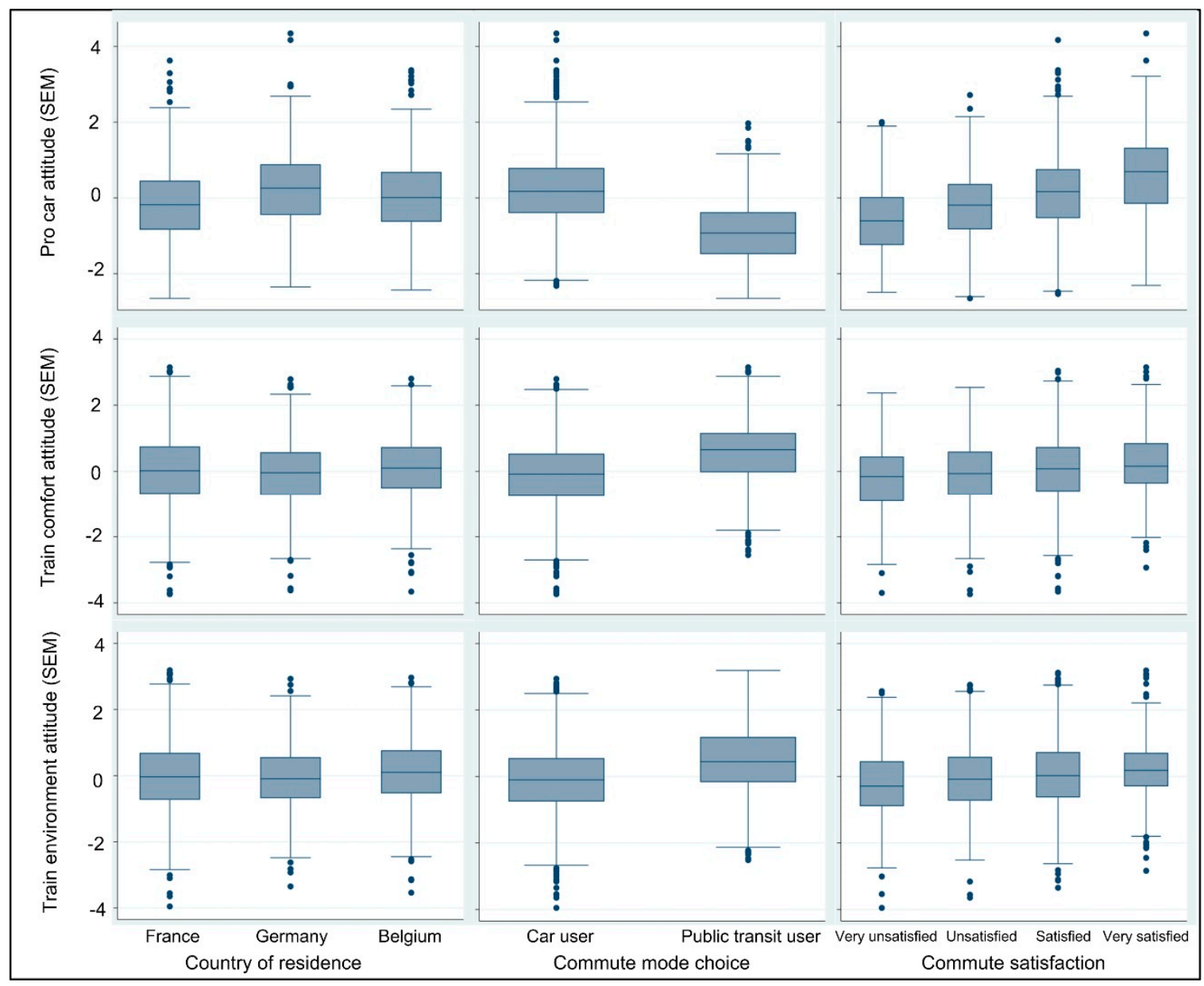

Figure A1. Box plots of transportation modes-related attitudes.

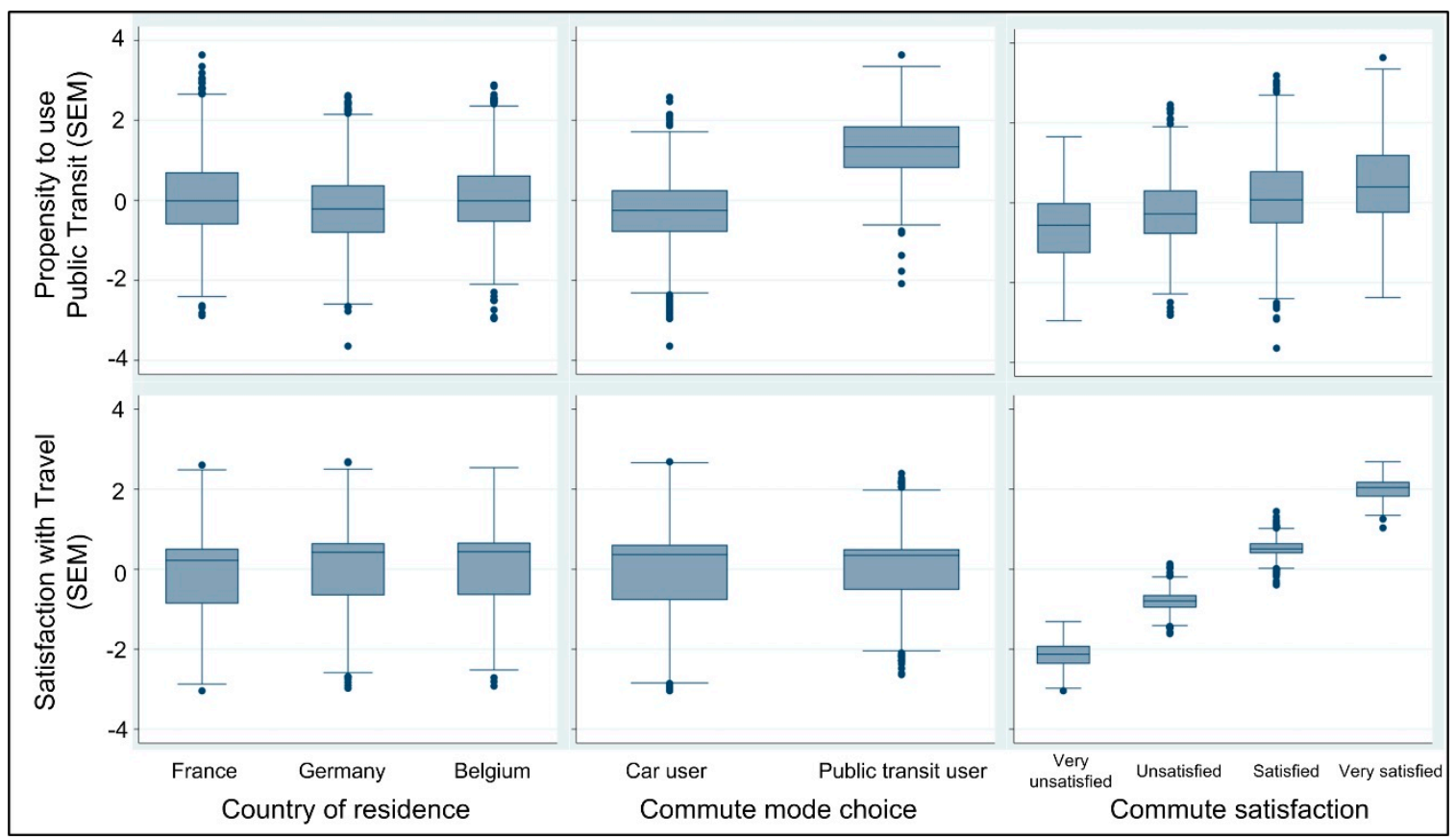

Figure A2. Box plots of propensity to use PT and satisfaction with travel. 


\section{References}

1. Möller, C.; Alfredsson-Olsson, E.; Ericsson, B.; Overvåg, K. The border as an engine for mobility and spatial integration: A study of commuting in a Swedish-Norwegian context. Nor. Geogr. Tidsskr. Nor. J. Geogr. 2018, 72, 217-233. [CrossRef]

2. Ravalet, E.; Vincent-Geslin, S.; Dubois, Y. Job-related “high mobility” in times of economic crisis: Analysis from four European countries. J. Urban Aff. 2017, 39, 563-580. [CrossRef]

3. Sandow, E. Til Work Do Us Part: The Social Fallacy of Long-distance Commuting. Urban Stud. 2013. [CrossRef]

4. Rapino, M.A.; Fields, A.K. Mega Commuters in the U.S.: Time and Distance in Defining the Long Commute Using the American Community Survey. Available online: https://www.census.gov/content/dam/Census/ library/working-papers/2013/demo/SEHSD-WP2013-03.pdf (accessed on 4 November 2020).

5. Wang, Q.; Hu, H. Rise of Interjurisdictional Commuters and Their Mode Choice: Evidence from the Chicago Metropolitan Area. J. Urban Plan. Dev. 2017, 143, 05017004. [CrossRef]

6. He, M.; Zhao, S. Determinants of long-duration commuting and long-duration commuters' perceptions and attitudes toward commuting time: Evidence from Kunming, China. IATSS Res. 2017, 41, 22-29. [CrossRef]

7. Zhu, Z.; Li, Z.; Chen, H.; Liu, Y.; Zeng, J. Subjective well-being in China: How much does commuting matter? Transportation 2019, 46, 1505-1524. [CrossRef]

8. Haas, A.; Osland, L. Commuting, Migration, Housing and Labour Markets: Complex Interactions. Urban Stud. 2014. [CrossRef]

9. De Vos, J.; Ettema, D.; Witlox, F. Effects of changing travel patterns on travel satisfaction: A focus on recently relocated residents. Travel Behav. Soc. 2019, 16, 42-49. [CrossRef]

10. Marion, B.; Horner, M.W. Comparison of Socioeconomic and Demographic Profiles of Extreme Commuters in Several U.S. Metropolitan Statistical Areas. Transp. Res. Rec. 2007. [CrossRef]

11. Turcotte, M. Like commuting? Workers' perceptions of their daily commute. Can. Soc. Trends 2005, 11-008, 35-41.

12. Vincent-Geslin, S.; Ravalet, E. Determinants of extreme commuting. Evidence from Brussels, Geneva and Lyon. J. Transp. Geogr. 2016, 54, 240-247. [CrossRef]

13. Moss, M.; Qing, C. The Emergence of the Super-Commuter. 2012. Available online: https://wagner.nyu.edu/ files/rudincenter/supercommuter_report.pdf (accessed on 4 November 2020).

14. Sandow, E.; Westin, K. The persevering commuter-Duration of long-distance commuting. Transp. Res. Part. Policy Pract. 2010, 44, 433-445. [CrossRef]

15. Joly, I.; Vincent-Geslin, S. Intensive travel time: An obligation or a choice? Eur. Transp. Res. Rev. 2016, 8, 10. [CrossRef]

16. Schmitz, F.; Drevon, G.; Gerber, P. La Mobilité des Frontaliers du Luxembourg: Dynamiques et Perspectives; Les Cahiers du CEPS/INSTEAD; Hors-Série: Luxembourg, 2012; ISSN 2077-3048.

17. De Vos, J.; Witlox, F. Travel satisfaction revisited. On the pivotal role of travel satisfaction in conceptualising a travel behaviour process. Transp. Res. Part. Policy Pract. 2017, 106, 364-373. [CrossRef]

18. Ye, R.; Titheridge, H. Satisfaction with the commute: The role of travel mode choice, built environment and attitudes. Transp. Res. Part. Transp. Environ. 2017, 52, 535-547. [CrossRef]

19. Grimal, R. Mobilité à longue distance: Plus de voyages s'effectuent en train, mais les seniors restent adeptes de la voiture. In La Mobilité des Français Panorama issu de L'enquête Nationale Transports et Déplacements 2008; Ministère de la Transition Ecologique: Paris, France, 2010; pp. 123-150.

20. Limtanakool, N.; Dijst, M.; Schwanen, T. The influence of socioeconomic characteristics, land use and travel time considerations on mode choice for medium- and longer-distance trips. J. Transp. Geogr. 2006, 14, 327-341. [CrossRef]

21. Orfeuil, J.-P. La mobilité locale: Toujours plus loin et plus vite. In Les Territoires de La Mobilité; Presses Universitaires de France: Paris, France, 2000; pp. 53-68. ISBN 978-2-13-050644-7.

22. Swedish Institute for Transport and Communications Analysis. In Transport and Communications: Yearbook 2005; SIKA: Stockholm, Sweden, 2005; ISBN 978-91-89586-50-5.

23. Meil, G. Summary, Job Mobility in Europe: Greater Differences among Social Groups than among Countries. In Mobile Living Across Europe I: Relevance and Diversity of Job-Related Spatial Mobility in Six European Countries; Barbara Budrish Publishers: Leverkusen, Germany, 2008; pp. 305-318.

24. Gorman-Murray, A.; Bissell, D. Mobile work, multilocal dwelling and spaces of wellbeing. Health Place 2018, 51, 232-238. [CrossRef] 
25. Nicholas, C.; Murphy, L.; Blackman, A. Exploring the dimensions of social capital that are effective mediators of long distance commuting impacts on wellbeing. Resour. Policy 2019, 60, 185-197. [CrossRef]

26. Huber, P.; Nowotny, K. Moving across Borders: Who is Willing to Migrate or to Commute? Reg. Stud. 2013, 47, 1462-1481. [CrossRef]

27. Paredes, D.; Soto, J.; Fleming, D.A. Wage compensation for fly-in/fly-out and drive-in/drive-out commuters. Pap. Reg. Sci. 2018, 97, 1337-1353. [CrossRef]

28. Albrecht, S.L.; Anglim, J. Employee engagement and emotional exhaustion of fly-in-fly-out workers: A diary study. Aust. J. Psychol. 2018, 70, 66-75. [CrossRef]

29. Fries-tersch, E.; Bradley, H.; Tugran, T. 2016 Annual Report on Intra-EU Labour Mobility; Publications Office: Luxembourg, 2017.

30. Nerb, G.; Hitzelsberger, F.; Woidich, A.; Pommer, S.; Hemmer, S.; Heczko, P. Scientific Report on the Mobility of Cross-Border Workers within the EU-27/EEA/EFTA Countries; European Commission DG Employment and Social Affairs: Brussells, Belgium, 2009; p. 97.

31. Fornell, C.; Johnson, M.D.; Anderson, E.W.; Cha, J.; Bryant, B.E. The American Customer Satisfaction Index: Nature, Purpose, and Findings. J. Mark. 1996, 60, 7-18. [CrossRef]

32. De Vos, J.; Mokhtarian, P.L.; Schwanen, T.; Van Acker, V.; Witlox, F. Travel mode choice and travel satisfaction: Bridging the gap between decision utility and experienced utility. Transportation 2016, 43, 771-796. [CrossRef]

33. Ettema, D.; Gärling, T.; Eriksson, L.; Friman, M.; Olsson, L.E.; Fujii, S. Satisfaction with travel and subjective well-being: Development and test of a measurement tool. Transp. Res. Part F Traffic Psychol. Behav. 2011, 14, 167-175. [CrossRef]

34. Morris, E.A.; Guerra, E. Mood and mode: Does how we travel affect how we feel? Transportation 2015, 42, 25-43. [CrossRef]

35. Olsson, L.E.; Gärling, T.; Ettema, D.; Friman, M.; Fujii, S. Happiness and Satisfaction with Work Commute. Soc. Indic. Res. 2013, 111, 255-263. [CrossRef] [PubMed]

36. Stone, A.A.; Schneider, S. Commuting episodes in the United States: Their correlates with experiential wellbeing from the American Time Use Survey. Transp. Res. Part F Traffic Psychol. Behav. 2016, 42, 117-124. [CrossRef]

37. Stutzer, A.; Frey, B.S. Commuting and Life Satisfaction in Germany. Inf. Raum. 2007, 2/3, 1-11.

38. Drobnič, S.; Beham, B.; Präg, P. Good Job, Good Life? Working Conditions and Quality of Life in Europe. Soc. Indic. Res. 2010, 99, 205-225. [CrossRef]

39. Novaco, R.W.; Stokols, D.; Milanesi, L. Objective and subjective dimensions of travel impedance as determinants of commuting stress. Am. J. Community Psychol. 1990, 18, 231-257. [CrossRef]

40. Hilbrecht, M.; Smale, B.; Mock, S.E. Highway to health? Commute time and well-being among Canadian adults. World Leis. J. 2014, 56,151-163. [CrossRef]

41. Ory, D.T.; Mokhtarian, P.L.; Redmond, L.S.; Salomon, I.; Collantes, G.O.; Choo, S. When is Commuting Desirable to the Individual? Growth Change 2004, 35, 334-359. [CrossRef]

42. Redmond, L.S.; Mokhtarian, P.L. The positive utility of the commute: Modeling ideal commute time and relative desired commute amount. Transportation 2001, 28, 179-205. [CrossRef]

43. Chng, S.; White, M.; Abraham, C.; Skippon, S. Commuting and wellbeing in London: The roles of commute mode and local public transport connectivity. Prev. Med. 2016, 88, 182-188. [CrossRef]

44. De Vos, J. Satisfaction-induced travel behaviour. Transp. Res. Part F Traffic Psychol. Behav. 2019, 63, 12-21. [CrossRef]

45. Wener, R.E.; Evans, G.W. Comparing stress of car and train commuters. Transp. Res. Part F Traffic Psychol. Behav. 2011, 14, 111-116. [CrossRef]

46. Cox, T.; Houdmont, J.; Griffiths, A. Rail passenger crowding, stress, health and safety in Britain. Transp. Res. Part A Policy Pract. 2006, 40, 244-258. [CrossRef]

47. Dickerson, A.; Hole, A.R.; Munford, L.A. The relationship between well-being and commuting revisited: Does the choice of methodology matter? Reg. Sci. Urban Econ. 2014, 49, 321-329. [CrossRef]

48. Morris, E.A.; Zhou, Y. Are long commutes short on benefits? Commute duration and various manifestations of well-being. Travel Behav. Soc. 2018, 11, 101-110. [CrossRef]

49. Higgins, C.D.; Sweet, M.N.; Kanaroglou, P.S. All minutes are not equal: Travel time and the effects of congestion on commute satisfaction in Canadian cities. Transportation 2018, 45, 1249-1268. [CrossRef]

50. Sposato, R.G.; Röderer, K.; Cervinka, R. The influence of control and related variables on commuting stress. Transp. Res. Part F Traffic Psychol. Behav. 2012, 15, 581-587. [CrossRef]

51. Jain, J.; Lyons, G. The gift of travel time. J. Transp. Geogr. 2008, 16, 81-89. [CrossRef] 
52. Gatersleben, B.; Uzzell, D. Affective Appraisals of the Daily Commute Comparing Perceptions of Drivers, Cyclists, Walkers, and Users of Public Transport. Environ. Behav. 2007, 39, 416-431. [CrossRef]

53. Lanzini, P.; Khan, S.A. Shedding light on the psychological and behavioral determinants of travel mode choice: A meta-analysis. Transp. Res. Part F Traffic Psychol. Behav. 2017, 48, 13-27. [CrossRef]

54. Gärling, T.; Gillholm, R.; Gärling, A. Reintroducing attitude theory in travel behavior research: The validity of an interactive interview procedure to predict car use. Transportation 1998, 25, 129-146. [CrossRef]

55. Kuppam, A.R.; Pendyala, R.M.; Rahman, S. Analysis of the Role of Traveler Attitudes and Perceptions in Explaining Mode-Choice Behavior. Transp. Res. Rec. 1999. [CrossRef]

56. Anable, J.; Gatersleben, B. All work and no play? The role of instrumental and affective factors in work and leisure journeys by different travel modes. Transp. Res. Part A Policy Pract. 2005, 39, 163-181. [CrossRef]

57. Schwanen, T.; Lucas, K. Understanding Auto Motives. In Auto Motives: Understanding Car Use Behaviours; Lucas, K., Blumenberg, E., Weinberger, R., Eds.; Emerald: Bingley, UK, 2011; pp. 3-38. ISBN 978-0-85724-233-4.

58. Beck, M.J.; Hess, S. Willingness to accept longer commutes for better salaries: Understanding the differences within and between couples. Transp. Res. Part A Policy Pract. 2016, 91, 1-16. [CrossRef]

59. Bienvenue, J.; Gerber, P. Echantillonnage Spatial et Production de Données D'enquête à L'échelle Intra-Urbaine d'une Ville Moyenne. L'exemple de la Capitale du Grand-Duché de Luxembourg; Cahiers GEODE; CEPS/INSTEAD: Luxembourg, 2003; 22p.

60. Enaux, C.; Gerber, P. Beliefs about energy, a factor in daily ecological mobility? J. Transp. Geogr. 2014, 41, 154-162. [CrossRef]

61. Gerber, P.; Thériault, M.; Enaux, C.; Carpentier-Postel, S. Modelling impacts of beliefs and attitudes on mode choices. Lessons from a survey of Luxembourg cross-border commuters. Transp. Res. Procedia 2018, 32, 513-523. [CrossRef]

62. Hoyle, R.H. Handbook of Structural Equation Modeling; The Guilford Press: New York, NY, USA, 2012; pp. 11-740.

63. Satorra, A.; Bentler, P.M. Corrections to test statistics and standard errors in covariance structure analysis. In Latent Variables Analysis: Applications for Developmental Research; Sage Publications, Inc.: Thousand Oaks, CA, USA, 1994; pp. 399-419. ISBN 978-0-8039-5330-7.

64. Hosmer, D.; Stanley, L. Applied Logistic Regression, 2d ed.; John Wiley \& Sons: New York, NY, USA, 2000.

65. Gould, W.; Pitblado, J.; Poi, B. Maximum Likelihood Estimation with Stata; StataCorp LP: College Station, TX, USA, 2010.

66. MacKinnon, J.G.; Davidson, R. Econometric Theory and Methods: International Edition; Oxford University Press: Oxford, UK, 2008.

67. De Bres, J. Competing language ideologies about societal multilingualism among cross-border workers in Luxembourg. Int. J. Sociol. Lang. 2014, 2014, 119-137. [CrossRef]

68. Enaux, C.; Gerber, P. Les déterminants de la représentation transnationale du bassin de vie. Une approche fondée sur l'attachement au lieu des frontaliers luxembourgeois. Rev. Econ. Région. Urbaine 2008, 725-752. [CrossRef]

69. Zhu, J.; Fan, Y. Daily travel behavior and emotional well-being: Effects of trip mode, duration, purpose, and companionship. Transp. Res. Part A Policy Pract. 2018, 118, 360-373. [CrossRef]

70. Roberts, J.; Hodgson, R.; Dolan, P. "It's driving her mad": Gender differences in the effects of commuting on psychological health. J. Health Econ. 2011, 30, 1064-1076. [CrossRef]

71. Cao, J.; Ettema, D. Satisfaction with travel and residential self-selection: How do preferences moderate the impact of the Hiawatha Light Rail Transit line? J. Transp. Land Use 2014, 7, 93-108. [CrossRef]

72. Mouratidis, K.; Ettema, D.; Næss, P. Urban form, travel behavior, and travel satisfaction. Transp. Res. Part A Policy Pract. 2019, 129, 306-320. [CrossRef]

73. Ye, R.; Titheridge, H. The determinants of commuting satisfaction in low-income population: A case study of Xi'an, China. Travel Behav. Soc. 2019, 16, 272-283. [CrossRef]

74. Choe, C.; Van Kerm, P. Foreign Workers and the Wage Distribution: What Does the Influence Function Reveal? Econometrics 2018, 6, 41. [CrossRef]

75. Heinen, E.; Bohte, W. Multimodal Commuting to Work by Public Transport and Bicycle: Attitudes toward Mode Choice. Transp. Res. Rec. 2014, 2468, 111-122. [CrossRef]

76. Ye, R.; De Vos, J.; Ma, L. Analysing the association of dissonance between actual and ideal commute time and commute satisfaction. Transp. Res. Part A Policy Pract. 2020, 132, 47-60. [CrossRef] 
77. De Vos, J. The effect of COVID-19 and subsequent social distancing on travel behavior. Transp. Res. Interdiscip. Perspect. 2020, 5, 100121. [CrossRef]

78. Hu, L.; Bentler, P.M. Cutoff criteria for fit indexes in covariance structure analysis: Conventional criteria versus new alternatives. Struct. Equ. Model. 1999, 6, 1-55. [CrossRef]

Publisher's Note: MDPI stays neutral with regard to jurisdictional claims in published maps and institutional affiliations.

(C) 2020 by the authors. Licensee MDPI, Basel, Switzerland. This article is an open access article distributed under the terms and conditions of the Creative Commons Attribution (CC BY) license (http://creativecommons.org/licenses/by/4.0/). 